\title{
UTILIZAÇÃO DA SUBSTITUIÇÃO PARCIAL DO CIMENTO POR CINZA LEVE DO BAGAÇO DE CANA-DE-ACÚ- CAR EM CONCRETOS
}

\author{
Liri Yoko Cruz Prieto Hojo (UEM); \\ Carlos Humberto Martins, Dr. (UEM)
}

\section{RESUMO}

A cinza volante é um resíduo gerado a partir da queima do bagaço de cana-de-açúcar nas caldeiras para a co-geração de energia elétrica. O objetivo do trabalho foi analisar a pozolanicidade da cinza volante, aplicá-la em corpos-de-prova de concreto com substituições parciais do cimento Portland de $0 \%, 2,5 \%$, $5 \%, 7,5 \%$ e $10 \%$ para avaliar sua resistência mecânica e analisar a microscopia desses concretos por meio dos ensaios de microscopia eletrônica de varredura (MEV). Foram definidos dois traços para elaborar os corpos-de-prova com substituições, um com consumo de cimento normal e outro traço rico. Os resultados comprovaram que a cinza tem o índice de atividade pozolânica superior ao mínimo exigido, nos ensaios de resistência à compressão, os corpos-de-prova do traço normal com substituição de até 7,5\% de cimento por cinza volante apresentaram uma resistência de $29 \mathrm{MPa}$, semelhante ao traço de referência (0\%), e, houve uma redução no consumo de cimento de $367 \mathrm{~kg} / \mathrm{m} 3$ para $339 \mathrm{~kg} / \mathrm{m} 3$. Os ensaios de MEV comprovaram que quanto maior a substituição maior será os componentes de zona de transição como a portlandita e a etringita, em comparação com o silicato de cálcio hidratado que confere resistência ao concreto.

\footnotetext{
ABSTRACT

Fly ash is a waste from the sugarcane bagasse burn process for electric power co-generation. This study was developed in order to analyze the fly ashes' pozzolanic potential, by the application of different substitutions percentiles of Portland - starting with 0\%, 2,5\%,5\%,7,5\% until 10\% - in concrete specimens aiming the evaluation of its mechanical strength and microscopically analyze through microscopy electron assays (SEM). It has been defined two mix proportions to the specimen with substitutions, one of these with regular cement proportion and other with rich mix proportion. The results has shown that fly ashes has higher pozzolanic activity levels than the minimum required on the compressive strength tests, the regular mix-proportion specimens with substitution up to 7,5\% of cement by fly ash showed a 29MPa resistance, similar to the standard (0\%), and there was also a reduction on the cement consumption from $367 \mathrm{~kg} / \mathrm{m}^{3}$ to $339 \mathrm{~kg} / \mathrm{m}^{3}$. The SEM tests showed that the higher the substitution percentiles the bigger the transitional zone components as the portladite and ettringite will be in comparison with calcium silicate hydrate, which confers the concrete resistance.
} 


\section{INTRODUÇÃO}

O Brasil é o maior produtor de cana-de-açúcar do mundo, sendo sua produção destinada para açúcar e etanol. E, as indústrias desse segmento desenvolveram uma nova forma de gerar energia elétrica através da queima do bagaço de cana-de-açúcar o que produz eletricidade suficiente para suprir a demanda da usina devido a seu alto poder calorífico (SALES E LIMA, 2010).

O processo de queima do bagaço nas caldeiras é responsável por gerar dois tipos de cinza, uma proveniente do fundo das fornalhas (cinza pesada) e outra do lavador de gases acoplado à chaminé (cinza volante ou leve). No caso, a cinza utilizada para o estudo é proveniente do lavador de gases.

A partir desses dados, é possível estimar que a indústria sucroalcooleira é responsável por gerar 3,61 milhões de toneladas de cinza de bagaço de cana-de-açúcar (CBC), um volume significativo de resíduos, devido a sua alta produção. Esse resíduo pode substituir a adubação química recomendada desde que aplicado em doses corretas, e, por ser rico em nutrientes pode ser aproveitado em solo com baixa fertilidade natural para melhorar as características físico-químicas (FEITOSA, MALTONI e SILVIA, 2009). Entretanto, quando a usina não consegue aplicá-lo integralmente no campo deve se ter cuidado com a sua disposição inadequada no meio ambiente, isso pode causar assoreamento nos recursos hídricos e também diminuir a vida útil dos aterros.

A Lei $n^{\circ} 12.305: 2010$ que institui a Política Nacional de Resíduos Sólidos foi criada para a proteção da saúde pública e da qualidade ambiental; não geração, redução, reutilização, reciclagem, tratamento dos resíduos sólidos e a disposição final ambientalmente adequada. Esses objetivos da legislação estimulam e obrigam as indústrias a adotar um plano de gerenciamento de resíduos sólidos, fazer a destinação correta dos rejeitos e desenvolver tecnologias para reutilizar, reciclar e/ou tratar esses resíduos.
A aplicação desta Lei pode ser exemplificada por meio da seguinte citação, segundo Martins, Machado, Altoé (2011), uma das possíveis soluções para reduzir a poluição gerada na produção dos materiais de construção é a incorporação da CBC em substituição ao agregado miúdo (areia) e/ou ao cimento utilizado na fabricação de concretos de cimento Portland. A reciclagem da cinza será benéfica tanto para a indústria quanto para o meio ambiente, uma vez que, as usinas, ao fornecerem as cinzas, solucionam o problema da estocagem desse subproduto, que ocupa grande espaço no pátio, e a disposição em locais inadequados; e, o meio ambiente também é favorecido pois não receberá esse resíduo e reduzirá o consumo de matéria prima utilizada na fabricação do cimento.

As pozolanas podem contribuir para o ganho de resistência mecânica e redução de água para a trabalhabilidade devido o efeito físico das partículas na distribuição granulométrica do sistema (NITA, JOHN, 2007). A reciclagem de resíduos tem sido aplicada com sucesso no setor da construção civil, diversos resíduos são utilizados na fabricação de argamassas, concretos, blocos cerâmicos e pavers.

Enfim, este trabalho busca analisar a atividade pozolânica da cinza leve do bagaço de cana de açúcar de uma usina de co-geração de energia elétrica da região de Maringá - PR, para determinar a possibilidade da sua aplicação na substituição parcial do cimento Portland por essa cinza em concretos.

A incorporação da cinza volante nos concretos irá reduzir o consumo de recursos na construção civil, os impactos gerados na fabricação do cimento, promover créditos de carbono pela não geração de $\mathrm{CO} 2$ na fabricação do clínquer e solucionar o problema das usinas com estocagem e disposição final inadequada do resíduo, que podem causar o assoreamento dos cursos d'água e diminuir a vida útil dos aterros. 


\section{METODOLOGIA}

\subsection{CARACTERIZAÇÃO DOS MATERIAIS}

O ensaio de granulometria foi realizado para os agregados miúdo e graúdo segundo a ABNT NBR NM 248:2003 "Agregados - determinação da composição granulométrica". A determinação da massa unitária para os agregados foi realizada segundo a ABNT NBR NM 45:2006 "Agregados - Determinação da massa unitária e do volume de vazios". E, o ensaio de massa específica para o agregado miúdo foi realizado segundo a $A B N T$ NBR NM 52:2009 "Agregado miúdo - Determinação de massa específica e massa específica aparente" e para o agregado graúdo foi utilizado a ABNT NBR NM 53:2009 "Agregado graúdo - Determinação de massa específica, massa específica aparente e absorção de água".

A análise granulométrica da $C B C$ foi realizada de acordo com a ABNT NBR 7181/1988 "Solo - Análise granulométrica", por meio de sedimentação e peneiramento. $E$, a massa específica da $C B C$ foi determinada pela ABNT NBR NM 23:2001 "Cimento Portland e outros materiais em pó - Determinação da massa específica".

\subsection{ANÁLISE DA ATIVIDADE POZOLÂNICA DA CINZA VOLANTE}

A atividade pozolânica foi determinada pelo Método de Chapelle modificado por Raverdy et al (1980), seguindo a ABNT NBR 15895/2010 "Materiais pozolânicos - Determinação do teor de hidróxido de cálcio fixado - Método Chapelle modificado", realizado pelo Laboratório de Materiais de Construção do IPT-SP.

\subsection{MOLDAGEM E RESISTÊNCIA À COM- PRESSÃO DOS CORPOS-DE-PROVA DE CONCRETO}

Os ensaios de moldagem e cura dos corpos-de-prova foram realizados segundo a ABNT NBR 5738:2003 "Concreto - Procedimento para moldagem e cura de corpos-de-prova" e emenda ABNT NBR 5738:2008.

A elaboração do concreto com substituições parciais do cimento pela cinza volante foi realizada para dois traços: o primeiro traço com consumo normal de cimento ( $367,6 \mathrm{~kg} / \mathrm{m} 3$ de concreto) e o segundo um traço rico $(393,6 \mathrm{~kg} / \mathrm{m} 3$ de concreto).

O primeiro traço, denominado traço normal, foi realizado a partir do traço de referência desenvolvido por Nunes (2009) que utilizou a cinza pesada $1,000: 2,060: 2,940$ : 0,555 (cimento : areia : brita : água), esse traço possui um consumo de cimento de 367,56 $\mathrm{kg} / \mathrm{m} 3$ de concreto. O segundo traço, denominado traço rico, foi $1: 1,85: 2,65: 0,55$ (cimento : areia : brita : água), esse traço tem um consumo de cimento maior que o anterior, $393,60 \mathrm{~kg} / \mathrm{m} 3$ de concreto.

Em seguida foram elaborados corpos-de-prova com cinza volante nas proporções de $0 \%, 2,5 \%, 5,0 \%, 7,5 \%$ e $10 \%$ para ambos os traços, foram moldados doze corpos-de-prova cilíndricos de $10 \mathrm{~cm}$ X $20 \mathrm{~cm}$ para cada substituição. Foram analisados $\mathrm{opH}$ dos concretos no estado fresco, a consistência pelo abatimento do tronco de cone (Slump Test) foi determinada segundo a ABNT NBR NM 67:2003: "Concreto - Determinação da consistência pelo abatimento do tronco de cone.". Após a moldagem, os corpos-de-prova permaneceram em seus moldes por $24 \mathrm{~h}$ e, depois desse período, foram desmoldados e acondicionados em câmara úmida (temperatura $23 \pm 2^{\circ} \mathrm{C}$ e umidade relativa $95 \pm 5 \%$ ) até a idade de ruptura de 3,7 e 28 dias. Os ensaios de resistência à compressão foram realizados segundo a ABNT NBR 5739:2007 "Concreto - Ensaio de compressão de corpos-de-prova cilíndricos", em uma prensa 
hidráulica de capacidade de carga de 100 toneladas.

As Tabelas 1 e 2 apresentam o traço normal em massa e o traço rico em massa com as respectivas substituições.

Tabela 1 - Traço normal em massa

\begin{tabular}{|c|c|c|c|c|c|c|}
\hline Traço & \multicolumn{2}{|c|}{ Aglomerante } & Areia & Brita & Água & Fator a/ \\
& $\begin{array}{c}\text { Cimento } \\
\text { (kg) }\end{array}$ & Cinza (kg) & (kg) & (kg) & (I) & \\
\hline $0 \%$ & 7,26 & 0 & 14,9 & 21,3 & 4 & 0,55 \\
\hline $2,5 \%$ & 7,08 & 0,18 & 14,9 & 21,3 & 4 & 0,55 \\
\hline $5 \%$ & 6,9 & 0,36 & 14,9 & 21,3 & 4 & 0,55 \\
\hline $7,5 \%$ & 6,72 & 0,54 & 14,9 & 21,3 & 4 & 0,55 \\
\hline
\end{tabular}

Tabela 2 - Traço rico em massa

\begin{tabular}{|c|c|c|c|c|c|c|}
\hline Traço & \multicolumn{2}{|c|}{ Aglomerante } & Areia & Brita & Água & Fator a/ \\
& $\begin{array}{c}\text { Cimento } \\
\mathbf{( k g})\end{array}$ & Cinza (kg) & $\mathbf{( k g )}$ & $\mathbf{( k g )}$ & $\mathbf{( I )}$ & $\mathbf{a g}$ \\
\hline $0 \%$ & 7,34 & 0 & 13,57 & 19,45 & 4,04 & 0,55 \\
\hline $2,5 \%$ & 7,16 & 0,183 & 13,57 & 19,45 & 4,04 & 0,55 \\
\hline $5 \%$ & 6,97 & 0,367 & 13,57 & 19,45 & 4,04 & 0,55 \\
\hline $7,5 \%$ & 6,79 & 0,55 & 13,57 & 19,45 & 4,04 & 0,55 \\
\hline
\end{tabular}

Fonte: Autores.

\subsection{ANÁLISE POR MICROSCOPIA ELETRÔ- NICA DE VARREDURA}

As análises da microestrutura dos concretos para os diferentes traços e substituições foram realizadas com as amostras coletadas após o ensaio de resistência à compressão aos 28 dias, as quais foram submetidas à microscopia de varredura eletrônica (MEV).

$O$ ensaio foi realizado no Complexo de Centrais de Apoio à Pesquisa (COMCAP) da Universidade Estadual de Maringá, por meio de microscópio eletrônico de varredura de elétrons Superscan SS - 550 da marca Shimadzu, operando com tensão de aceleração de $10 \mathrm{kV}$, com capacidade de aumento de 60 a 6.000 vezes para fazer a caracterização da sua microestrutura.
A Figura 1 ilustra a moldagem dos corpos-de-prova com as substituições.

\section{RESULTADOS}

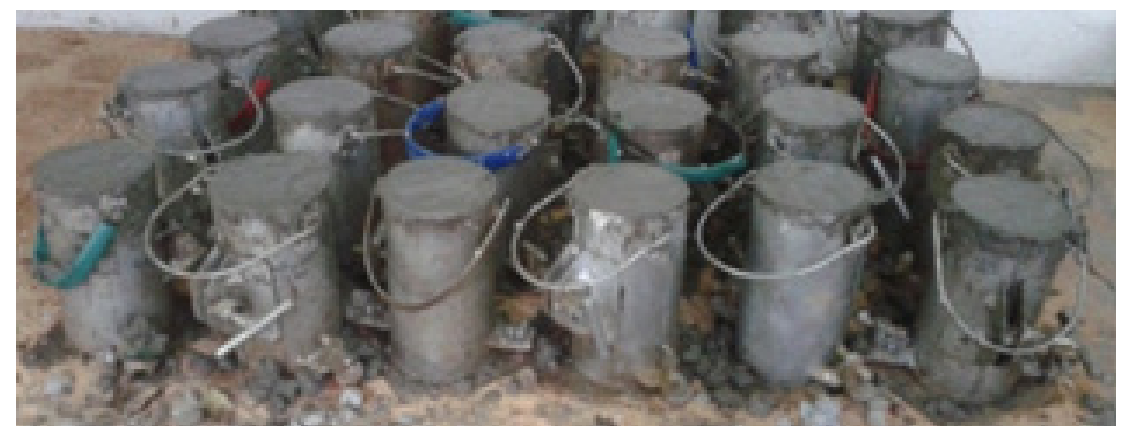

Fonte: Autores.

\subsection{CARACTERIZAÇÃO DOS MATERIAIS}

O agregado miúdo apresentou massa específica de $2,631 \mathrm{~g} / \mathrm{cm}^{3}$, massa unitária no estado solto de $1,548 \mathrm{~g} / \mathrm{cm}^{3}$, diâmetros máximo característico de 1,20 mm e módulo de finura de 1,90. A Figura 2 apre- 
Figura 2 - Curva de distribuição granulométrica do agregado miúdo

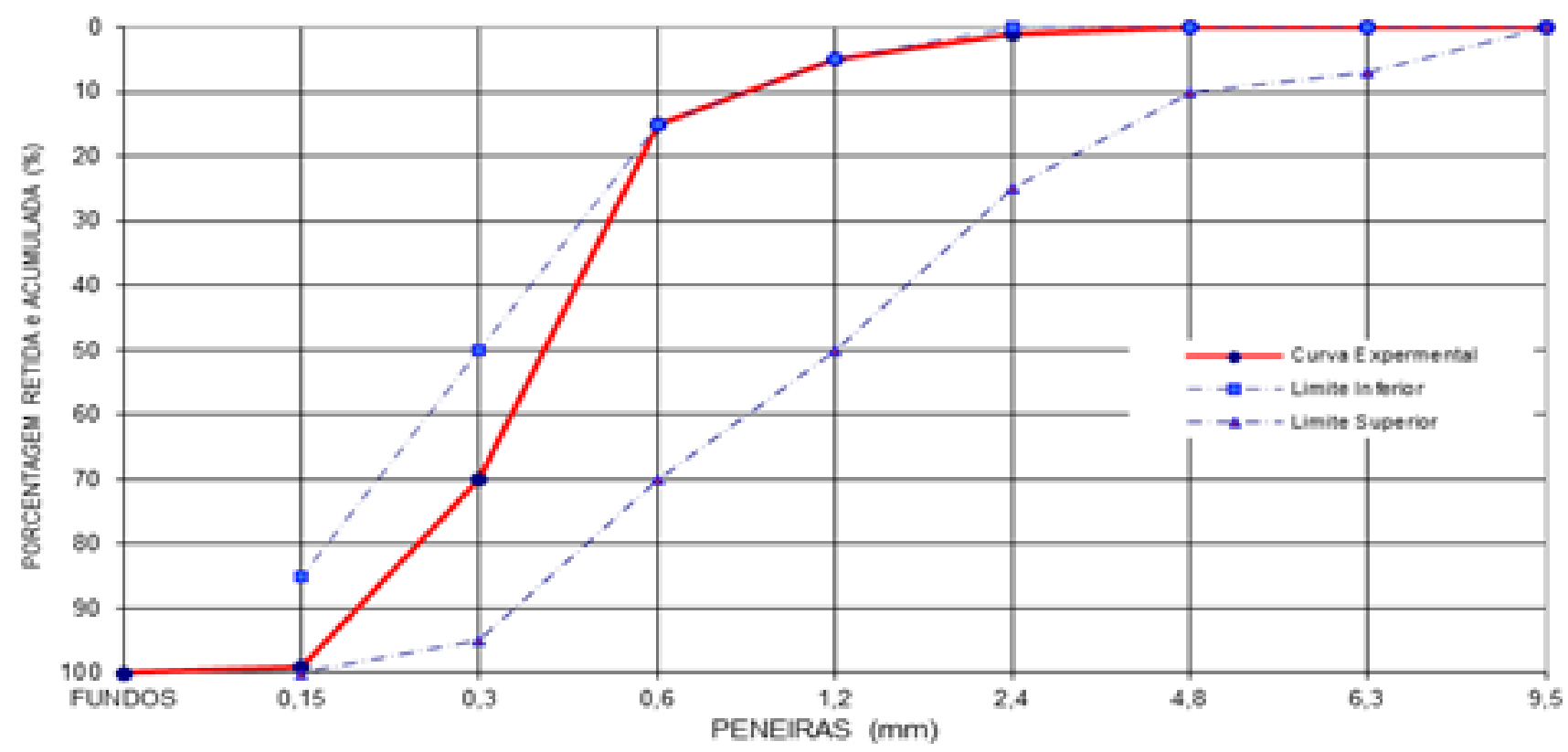

Fonte: Autores.

senta a curva de distribuição granulométrica do agregado miúdo.

O agregado graúdo apresentou massa específica de $2,746 \mathrm{~g} / \mathrm{cm}^{3}$, massa unitária no estado solto de $1,587 \mathrm{~g} / \mathrm{cm}^{3}$, diâmetros máximo característico de $19,0 \mathrm{~mm}$ e módulo de finura de 6,830. e a Figura 3 apresenta a curva de distribuição granulométrica.

A cinza apresentou massa específica de $2,49 \mathrm{~g} / \mathrm{cm}^{3}$ e a análise granulométrica da cinza volante foi realizada por sedimentação e peneiramento, segundo a ABNT NBR 7181:1988.

Figura 3 - Curva de distribuição granulométrica do agregado graúdo

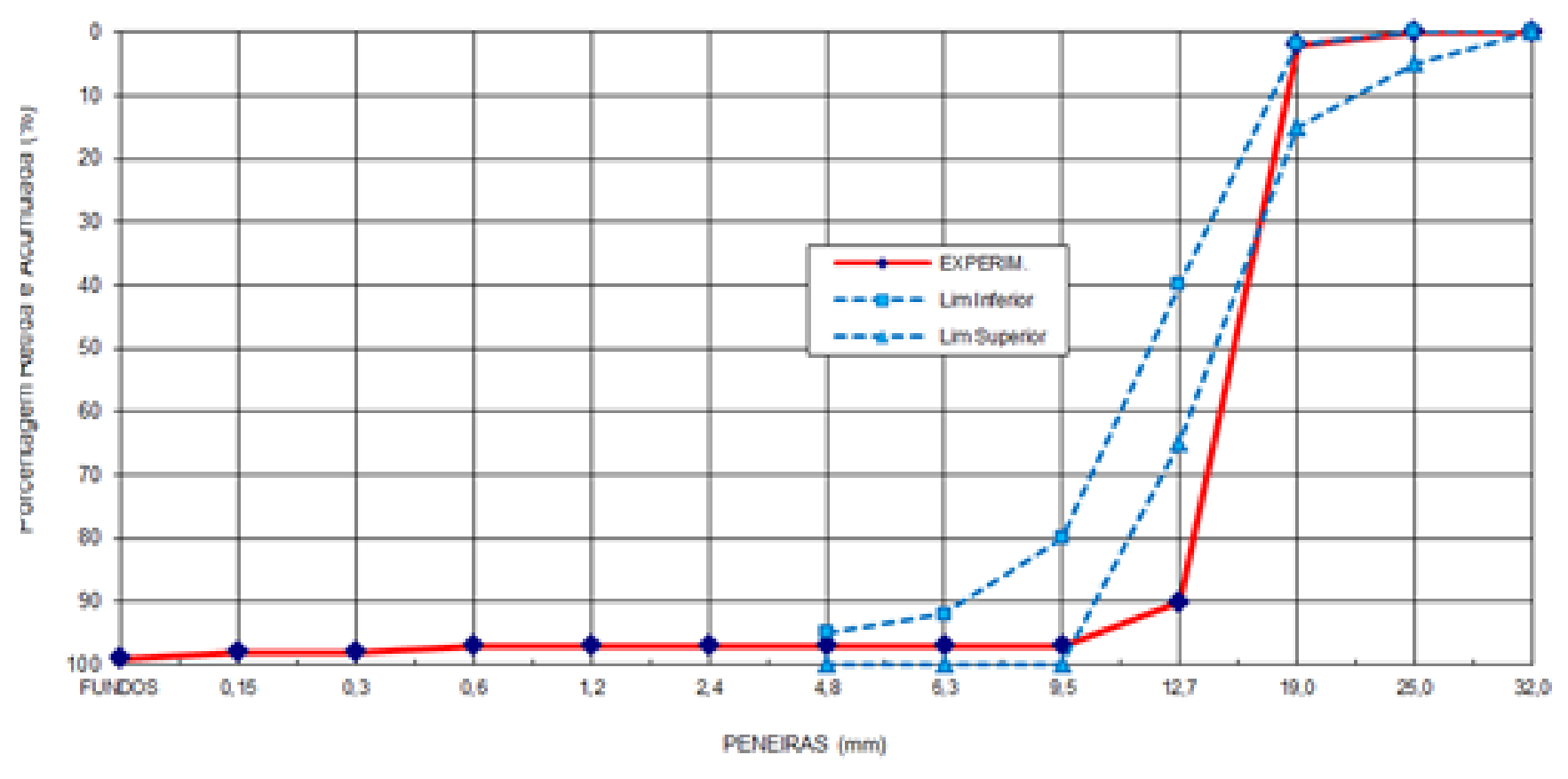


Figura 4 - Curva granulométrica da cinza volante



Class tea plo grovulomerica NER 6 SCS 950.002

\section{ARGLA \\ SLTE \\ 3.2. ANÁLISE DA ATIVIDADE POZOLÂNICA DA CINZA VOLANTE}

0.060

Fonte: Autores.

O índice de atividade pozolânica foi realizado segundo a ABNT NBR 15.895:2010 no IPT e o valor obtido foi de $480 \mathrm{mg} \mathrm{Ca}(\mathrm{OH}) 2 / \mathrm{g}$ amostra.

Esse resultado é maior que o valor mínimo exigido pela ABNT NBR 15.895:2010 de $436 \mathrm{mg} \mathrm{Ca}(\mathrm{OH})_{2} / \mathrm{g}$ amostra, portanto, este ensaio permite afirmar que a cinza volante possui atividade pozolânica.

\subsection{MOLDAGEM E RESISTÊNCIA À COM- PRESSÃO DOS CORPOS-DE-PROVA DE CONCRETO}

O traço normal utilizado para analisar as propriedades mecânicas foi $1: 2,06: 2,94: 0,55$ (cimento : areia : brita : água) de Nunes (2009). Inicialmente foi realizado um traço de referência ou "padrão" com $0 \%$ de substituição e, em seguida as substituições conforme apresenta a Tabela 3.

O fator a/ag foi determinado pela relação da água com o aglomerante, já que a cinza está substituindo o cimento. A análise do $\mathrm{pH}$ com as fitas de $\mathrm{pH}$ permitem afirmar que todos os corpos-de-prova apresentaram pH básico maior que 9,0 mesmo após a adição da cinza. Os valores obtidos nos ensaios de resistência à compressão axial são apresentados na Tabela 4. 
Tabela 3 - Quantidades de materiais e Slump Test do traço normal

\begin{tabular}{|c|c|c|c|c|c|c|c|c|c|}
\hline \multirow{2}{*}{ Traço } & \multicolumn{2}{|c|}{ Aglomerante } & \multirow{2}{*}{$\begin{array}{c}\text { Areia } \\
\text { (kg) }\end{array}$} & \multirow{2}{*}{$\begin{array}{l}\text { Brita } \\
\text { (kg) }\end{array}$} & \multirow{2}{*}{$\begin{array}{l}\text { Água } \\
\text { (L) }\end{array}$} & \multirow{2}{*}{$\begin{array}{l}\text { Fator } \\
\text { a/ag }\end{array}$} & \multirow{2}{*}{$\begin{array}{c}\text { Massa } \\
\text { espec. } \\
\left(\mathbf{k g} / \mathbf{m}^{3}\right)\end{array}$} & \multirow{2}{*}{$\begin{array}{l}\text { Consumo } \\
\text { de cimento } \\
\left(\mathrm{kg} / \mathrm{m}^{3}\right)\end{array}$} & \multirow{2}{*}{$\begin{array}{c}\text { Slump } \\
\text { Test } \\
\text { (cm) }\end{array}$} \\
\hline & $\begin{array}{l}\text { Cimento } \\
\text { (kg) }\end{array}$ & $\begin{array}{c}\text { Cinza } \\
\text { (kg) }\end{array}$ & & & & & & & \\
\hline $0 \%$ & 7,26 & 0 & 14,9 & 21,3 & 3,99 & 0,55 & 2402,30 & 367,56 & 5,5 \\
\hline $2,50 \%$ & 7,08 & 0,18 & 14,9 & 21,3 & 3,99 & 0,55 & 2400,57 & 358,19 & 4,0 \\
\hline $5 \%$ & 6,9 & 0,36 & 14,9 & 21,3 & 3,99 & 0,55 & 2398,84 & 348,83 & 4,5 \\
\hline $7,50 \%$ & 6,72 & 0,54 & 14,9 & 21,3 & 3,99 & 0,55 & 2397,12 & 339,49 & 3,5 \\
\hline $10 \%$ & 6,54 & 0,72 & 14,9 & 21,3 & 3,99 & 0,55 & 2395,40 & 330,16 & 3,0 \\
\hline
\end{tabular}

Tabela 4 - Resistência à compressão do traço normal

\begin{tabular}{|c|c|c|c|}
\hline \multirow{2}{*}{ \% de Cinza volante } & \multicolumn{3}{|c|}{$\mathrm{f}_{\mathrm{c}}$ (MPa) } \\
\cline { 2 - 4 } & \multicolumn{3}{|c|}{ Idade dos CP's } \\
\cline { 2 - 4 } & $\mathbf{3}$ dias & $\mathbf{7}$ dias & $\mathbf{2 8}$ dias \\
\hline $0 \%$ (Padrão) & 20,83 & 24,5 & 29,07 \\
\hline $2,5 \%$ & 18,56 & 25,6 & 29,53 \\
\hline $5 \%$ & 22,32 & 28,71 & 29,36 \\
\hline $7,5 \%$ & 17,7 & 23,81 & 27,79 \\
\hline $10 \%$ & 20,42 & 26,91 & \\
\hline
\end{tabular}

A Figura 5 ilustra a representação gráfica das resistências à compressão a 3, 7 e 28 dias para cada uma das substituições.

O gráfico confirma as características pozolânicas da cinza volante pois as resistências foram mantidas em $29 \mathrm{MPa}$. As resistências de 0\%, $2,5 \%, 5 \%$ e $7,5 \%$ aos 28 dias ficaram próximas de $29 \mathrm{MPa}$, apenas o traço de $10 \%$ obteve uma resistência inferior aos demais, $28 \mathrm{MPa}$. Logo, uma substituição de até $7,5 \%$ de cimento por cinza volante não compromete a resistência mecânica do concreto.

É importante ressaltar que o traço com substituição de $7,5 \%$ de cinza volante elaborado com um consumo de cimento de $339,5 \mathrm{~kg} / \mathrm{m}^{3}$ al- cançou resistência à compressão de 29,23 MPa, valor um pouco acima do traço padrão com $0 \%$ de cinza, com consumo de cimento de $367,6 \mathrm{~kg} /$ $\mathrm{m}^{3}$ e resistência de 29,07 MPa. Esses dados mostram que a substituição de cimento por cinza volante pode contribuir para redução no consumo de cimento nos concretos e argamassas, e também reduzir o impacto ambiental causado durante a fabricação do cimento.

A seguir é apresentado os resultados obtidos para o traço rico. O segundo traço utilizado para analisar as propriedades mecânicas foi 1 : $1,85: 2,65: 0,55$ (cimento : areia : brita : água). Inicialmente foi realizado um traço de referência ou "padrão" com $0 \%$ de substituição e, em seguida as substituições conforme apresenta a Tabela 5. 
Figura 5 - Resistência à compressão dos CP's do traço normal

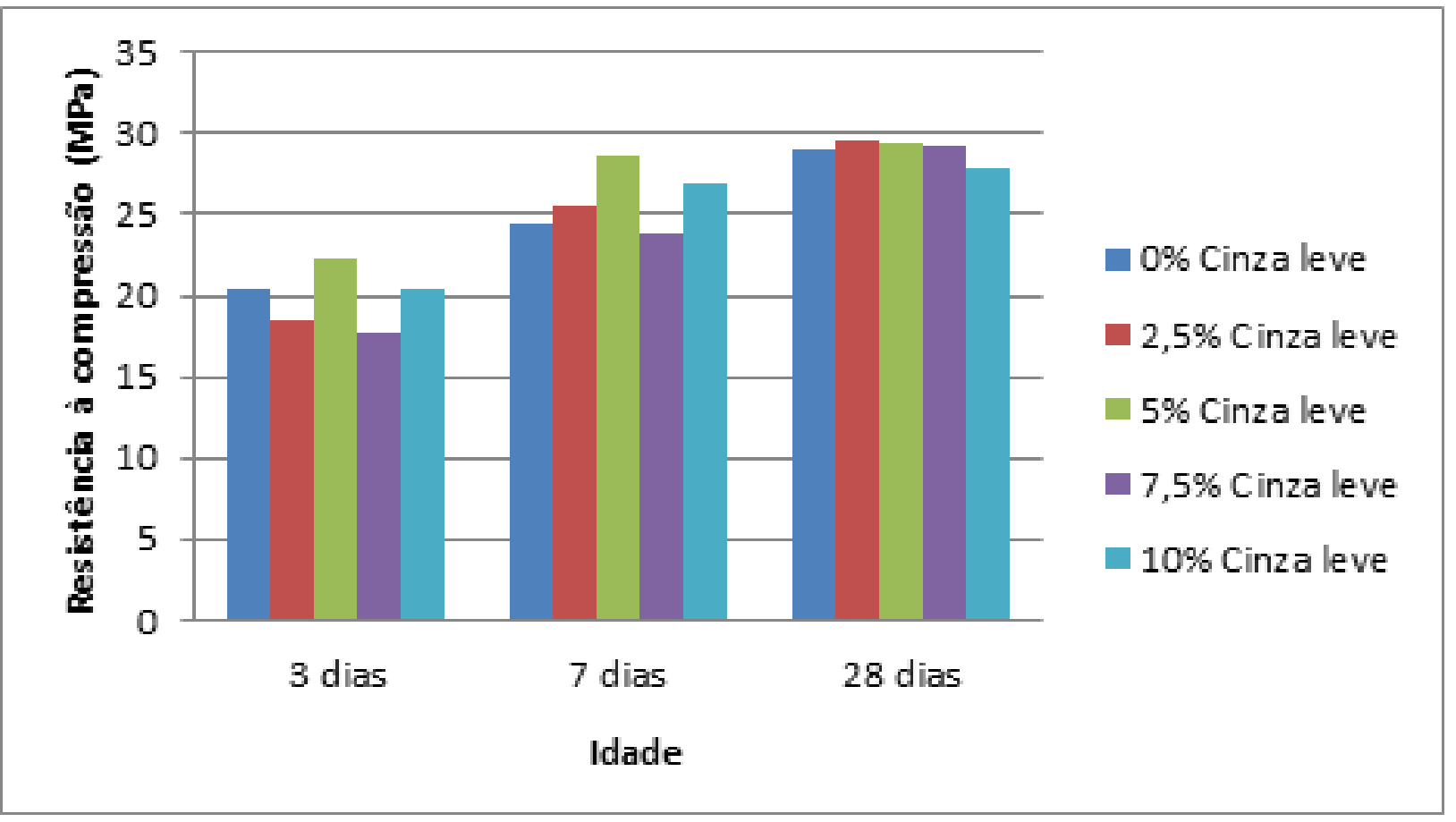

Fonte: Autores.

Tabela 5 - Quantidades de materiais e Slump Test do traço rico

\begin{tabular}{|c|c|c|c|c|c|c|c|c|c|}
\hline \multirow[t]{2}{*}{ Traço } & \multicolumn{2}{|c|}{ Aglomerante } & \multirow{2}{*}{$\begin{array}{c}\text { Areia } \\
\text { (kg) }\end{array}$} & \multirow{2}{*}{$\begin{array}{c}\text { Brita } \\
\text { (kg) }\end{array}$} & \multirow{2}{*}{$\begin{array}{l}\text { Água } \\
\text { (L) }\end{array}$} & \multirow{2}{*}{$\begin{array}{c}\text { Fator } \\
\text { a/ag }\end{array}$} & \multirow{2}{*}{$\begin{array}{c}\text { Massa } \\
\text { espec. } \\
\left(\mathbf{k g} / \mathbf{m}^{3}\right)\end{array}$} & \multirow{2}{*}{$\begin{array}{c}\text { Consumo } \\
\text { de } \\
\text { cimento } \\
\left(\mathrm{kg} / \mathrm{m}^{3}\right)\end{array}$} & \multirow{2}{*}{$\begin{array}{c}\text { Slump } \\
\text { Test } \\
\text { (cm) }\end{array}$} \\
\hline & $\begin{array}{c}\text { Cimento } \\
\text { (kg) }\end{array}$ & $\begin{array}{c}\text { Cinza } \\
\text { (kg) }\end{array}$ & & & & & & & \\
\hline $0 \%$ & 7,34 & 0 & 13,57 & 19,45 & 4,04 & 0,55 & 2380,89 & 393,60 & 7,0 \\
\hline $2,5 \%$ & 7,16 & 0,183 & 13,57 & 19,45 & 4,04 & 0,55 & 2379,08 & 383,63 & 6,5 \\
\hline $5 \%$ & 6,97 & 0,367 & 13,57 & 19,45 & 4,04 & 0,55 & 2377,15 & 373,20 & 6,0 \\
\hline $7,5 \%$ & 6,79 & 0,55 & 13,57 & 19,45 & 4,04 & 0,55 & 2375,35 & 363,26 & 5,5 \\
\hline $10 \%$ & 6,61 & 0,73 & 13,57 & 19,45 & 4,04 & 0,55 & 2373,55 & 353,36 & 5,0 \\
\hline
\end{tabular}

Tabela 6 - Resistência à compressão do traço rico

\begin{tabular}{|c|c|c|c|}
\hline \multirow{2}{*}{ \% de Cinza volante } & \multicolumn{3}{|c|}{$\mathrm{f}_{\mathrm{c}}$ (MPa) } \\
\cline { 2 - 4 } & \multicolumn{3}{|c|}{ Idade dos CP's } \\
\cline { 2 - 4 } & $\mathbf{3}$ dias & $\mathbf{7}$ dias & $\mathbf{2 8}$ dias \\
\hline $0 \%$ (Padrão) & 23,49 & 30,31 & 32,36 \\
\hline $2,5 \%$ & 20,59 & 28,02 & 31,2 \\
\hline $5 \%$ & 20,34 & 26,8 & 29,91 \\
\hline $7,5 \%$ & 20,16 & 27,51 & 30,48 \\
\hline $10 \%$ & 18,88 & 26,3 & 29,76 \\
\hline
\end{tabular}


O fator a/ag foi determinado pela relação da água com o aglomerante, já que a cinza está substituindo o cimento. A análise do $\mathrm{pH}$ com as fitas de $\mathrm{pH}$ permitem afirmar que todos os corpos-de-prova apresentaram pH básico maior que 9 , mesmo após a adição da cinza.

Os valores obtidos nos ensaios de resistência à compressão axial são apresentados na Tabela 6.

A Figura 6 apresenta a representação gráfica das resistências à compressão a 3, 7 e 28 dias para cada uma das substituições. traço rico, uma vez que, comparando com o traço normal no qual o consumo de cimento é menor, a substituição do cimento no traço rico se torna mais sensível e isso se reflete na resistência mecânica.

A partir das resistências obtidas nos dois traços foi elaborado um gráfico que apresenta as resistências em função do consumo de cimento, apresentado na Figura 7.

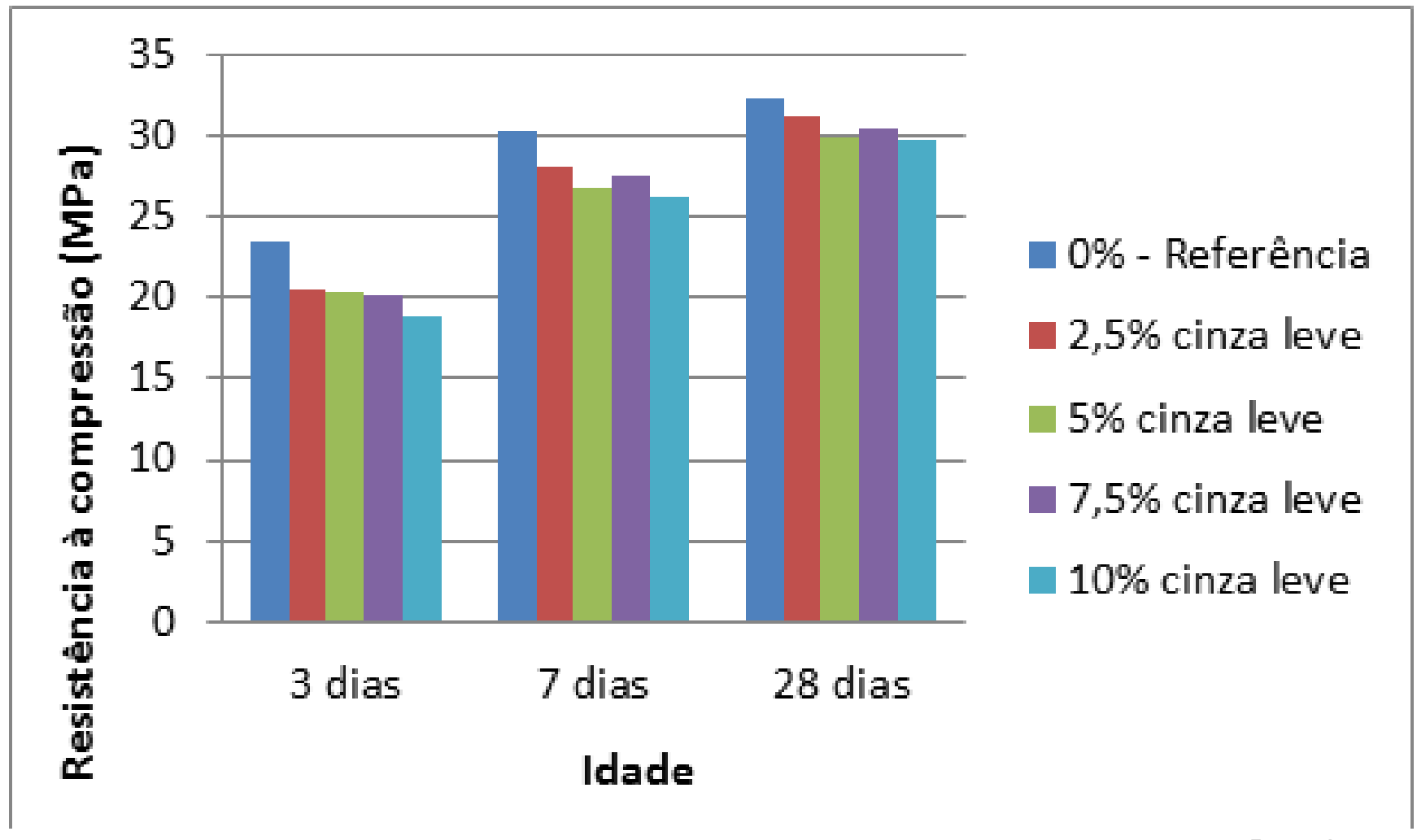

A análise do gráfico permite afirmar que houve um aumento regular das resistências aos 3, 7 e 28 dias, porém houve uma diminuição na resistência mecânica do concreto com a adição de cinza volante. O gráfico também evidencia que, apesar da cinza ter atividade pozolânica comprovada, a sua influência na perda de resistência é maior no 
Figura 7 - Consumo de cimento e resistência à compressão

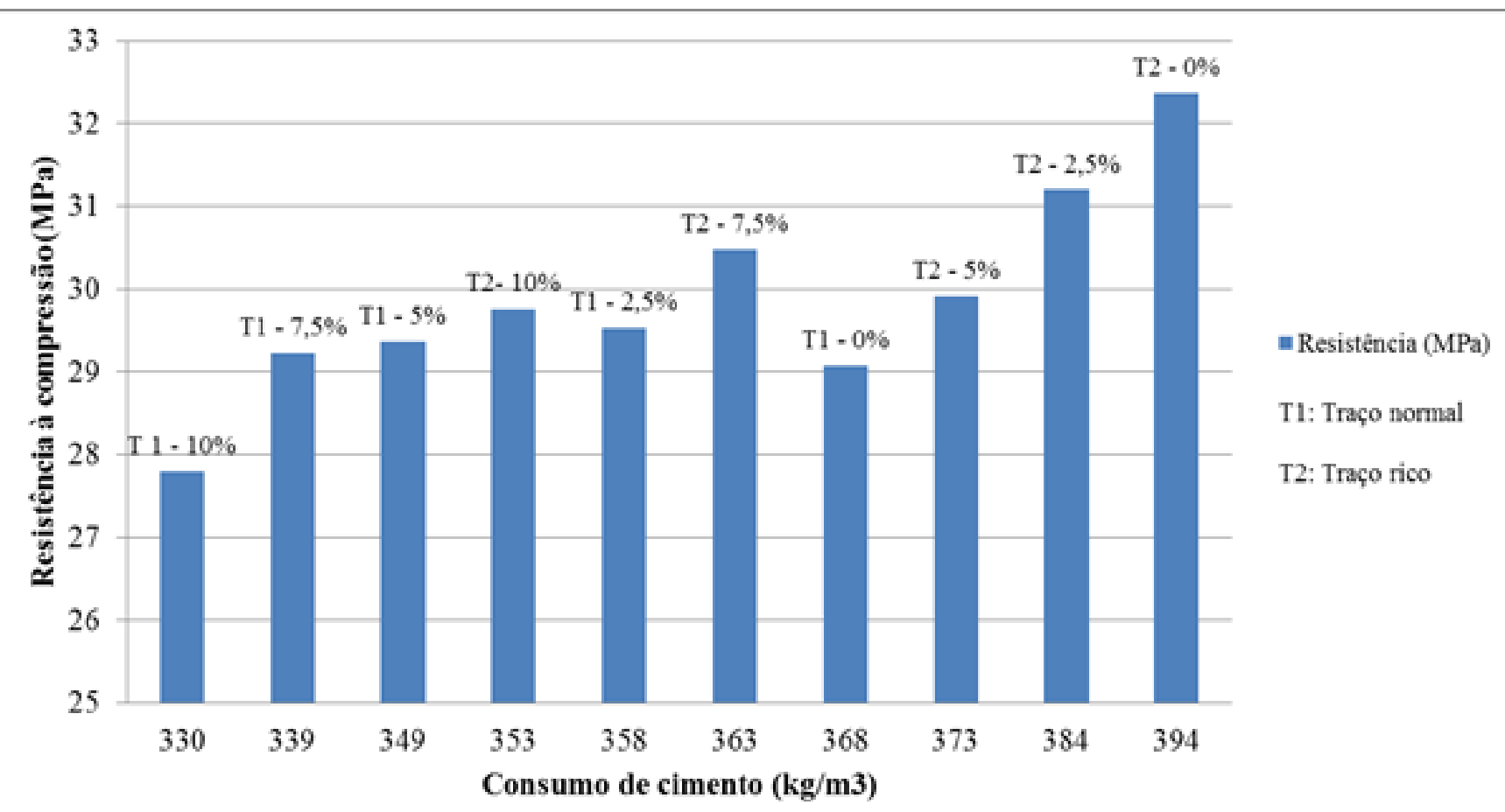

Fonte: Autores.

A análise do gráfico permite afirmar que o traço rico com $10 \%$ de cinza (T2 - 10\%) apresentou um consumo de cimento de $353,36 \mathrm{~kg} / \mathrm{m}^{3}$ e uma resistência de $29,76 \mathrm{MPa}$, sendo essa resistência semelhante ao traço normal com $2,5 \%$ de substituição ( $\mathrm{T} 1-2,5 \%)$, na qual o consumo de cimento foi de 358,19 $\mathrm{kg} / \mathrm{m}^{3}$ e a resistência $29,53 \mathrm{MPa}$, ou seja, apesar do traço ser rico, o consumo de cimento foi menor para uma resistência semelhante.

Observa-se também que no traço rico

Tabela 7 - Redução no custo e capacidade de produção de concreto para traço normal

\begin{tabular}{|c|c|c|c|c|}
\hline $\begin{array}{c}\text { Traço } \\
\text { normal }\end{array}$ & $\begin{array}{c}\text { Redução de } \\
\text { cimento/ } \\
\text { adição cinza } \\
\mathbf{( k g )}\end{array}$ & $\begin{array}{c}\text { Redução } \\
\text { preço (R\$) }\end{array}$ & $\begin{array}{c}\text { Produção } \\
\text { de } \\
\text { concreto } \\
\text { (m } \mathbf{3} / \mathbf{m e ̂ s})\end{array}$ & Resistência (MPa) \\
\hline $0 \%$ & 0,00 & 0,00 & ---- & 29,07 \\
\hline $2,5 \%$ & 9,37 & 5,25 & $21.769,30$ & 29,53 \\
\hline $5 \%$ & 18,73 & 10,49 & $10.892,48$ & 29,36 \\
\hline $7,5 \%$ & 28,07 & 15,72 & $7.266,88$ & 29,23 \\
\hline $10 \%$ & 37,40 & 20,95 & $5.454,08$ & 27,79 \\
\hline
\end{tabular}

Fonte: Autores.

com 7,5\% (T2 - 7,5\%) há um consumo de cimento $363,26 \mathrm{~kg} / \mathrm{m}^{3}$ e uma resistência de $30,48 \mathrm{MPa}$, sendo que essa resistência é semelhante à do traço original sem substituição (T1 - 0\%), na qual a resistência foi de 29,07 MPa, com um consumo de cimento de $367,56 \mathrm{~kg} / \mathrm{m}^{3}$, ou seja, o traço rico apresentou um consumo de cimento menor para uma resistência maior.

A Tabela 7 apresenta a redução de custos para a produção de $1 \mathrm{~m}^{3}$ concreto e a capacidade de produção de concreto pela quantidade de cinza volante gerada pela Cocamar para o traço normal. Essa tabela foi desenvolvida a partir dos dados da geração de cinza apresentados na revisão bibliográfica, que foi de 204 ton. cinza volante/mês em 2012 e do valor do cimento CP-II-F-32 utilizado 
no ensaio que foi de $R \$ 28,00$ o saco de 50 $\mathrm{kg}$.

A substituição de até $7,5 \%$ manteve a resistência em $29 \mathrm{MPa}$, isso representa uma redução de $R \$ 15,72$ no custo do $\mathrm{m} 3$ do concreto que atualmente varia de $R \$ 260$ a $R \$$ 300, uma redução significativa para o mercado.

A Tabela 8 apresenta a redução de cus-

Tabela 8 - Redução no custo e capacidade de produção de concreto para traço rico

\begin{tabular}{|c|c|c|c|c|}
\hline $\begin{array}{c}\text { Traço } \\
\text { rico }\end{array}$ & $\begin{array}{c}\text { Redução de } \\
\text { cimento/ } \\
\text { adição cinza } \\
\mathbf{( k g )}\end{array}$ & $\begin{array}{c}\text { Redução } \\
\text { preço (R\$) }\end{array}$ & $\begin{array}{c}\text { Produção } \\
\text { de } \\
\text { concreto } \\
\text { (m } / \mathbf{m e ̂ s )}\end{array}$ & $\begin{array}{c}\text { Resistência } \\
\text { (MPa) }\end{array}$ \\
\hline $0 \%$ & 0,00 & 0,00 & ---- & 32,36 \\
\hline $2,5 \%$ & 9,97 & 5,58 & $20.462,09$ & 31,2 \\
\hline $5 \%$ & 20,40 & 11,42 & $9.999,14$ & 29,91 \\
\hline $7,5 \%$ & 30,34 & 16,99 & $6.723,88$ & 30,48 \\
\hline $10 \%$ & 40,24 & 22,53 & $5.069,79$ & 29,76 \\
\hline
\end{tabular}

tos para a produção de $1 \mathrm{~m} 3$ concreto e a capacidade de produção de concreto pela quantidade de cinza volante gerada pela Cocamar para o traço rico.

Nesse traço houve uma redução na substituição do cimento que variou de 29 a $31 \mathrm{MPa}$. A substituição de até $10 \%$ representa uma redução de $\mathrm{R} \$ 22,53$ no custo do $\mathrm{m} 3$ do concreto que atualmente varia de $\mathrm{R} \$ 260$ a $\mathrm{R} \$ 300$, uma redução significativa para o mercado.

\subsection{ANÁLISE POR MICROSCOPIA ELETRÔ- NICA DE VARREDURA}

A seguir, são apresentadas as micrografias das amostras de concreto coletadas no ensaio de resistência à compressão com idade de 28 dias. A Figura 8 apresenta a matriz cimentícia aumentada $6.000 x$ para o con-
Fonte: Autores.

creto com consumo de cimento normal, as Figuras $8 \mathrm{a}, 8 \mathrm{~b}, 8 \mathrm{c}, 8 \mathrm{~d}$ e $8 \mathrm{e}$, representam as respectivas substituições de $0 \%, 2,5 \%, 5 \%$, $7,5 \%$ e $10 \%$.

As micrografias indicam que em todas as substituições foram encontrados o silicato de cálcio hidratado, a portlandia e a etringita em quantidades variadas. Os componentes da zona de transição visualizados nos traços de $0 \%$ a $7,5 \%$ são menos encontrados que no traço com $10 \%$ de cinza, o que comprovam a semelhança da resistência de $29 \mathrm{MPa}$ e a perda de resistência com $10 \%$ que foi de $28 \mathrm{MPa}$.

A seguir, são apresentadas as micrografias das amostras de concreto coletadas no ensaio de resistência à compressão com idade de 28 dias. A Figura 9 apresenta a matriz cimentícia aumentada $6.000 x$ para o concreto com consumo de cimento rico, as Figuras 9a, 9b, 9c, 9d e tivas substituições de $0 \%, 2,5 \%, 5 \%, 7,5 \%$ e $10 \%$.

As análises das Figuras apresentam que houve um crescimento na quantidade de etringita e portlandita em relação ao silicato de cálcio hidratado encontrado nas amostras, isso ocorreu devido ao aumento da porcentagem de substituição de cimento por cinza volante.

Essas análises do MEV reforçam a hipótese de que quanto mais rico for o traço, maior será a influência da cinza na substituição do cimento, ou seja, a cinza volante tende a reduzir a resistência à compressão nos traços ricos devido à formação de uma maior quantidade de etringita e portlandita ao invés do silicato de cálcio hidratado, que é responsável pelas propriedades mecânicas da pasta. 
Figura 8 - MEV do traço normal

(a)

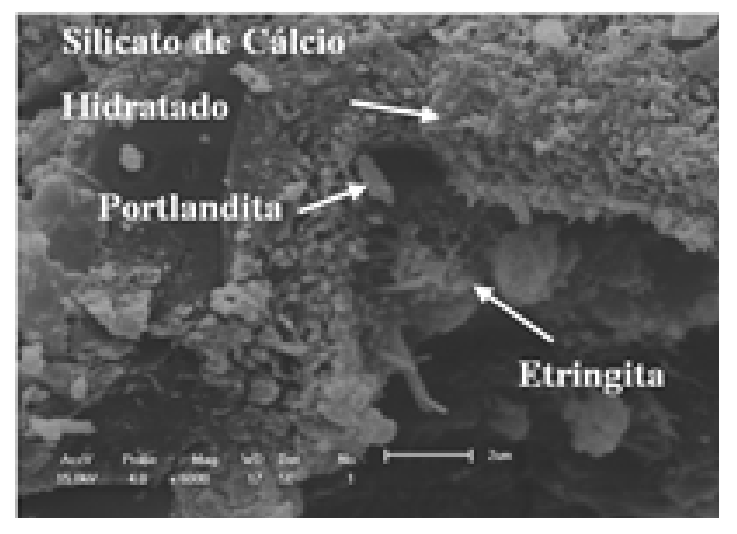

(c)



(b)

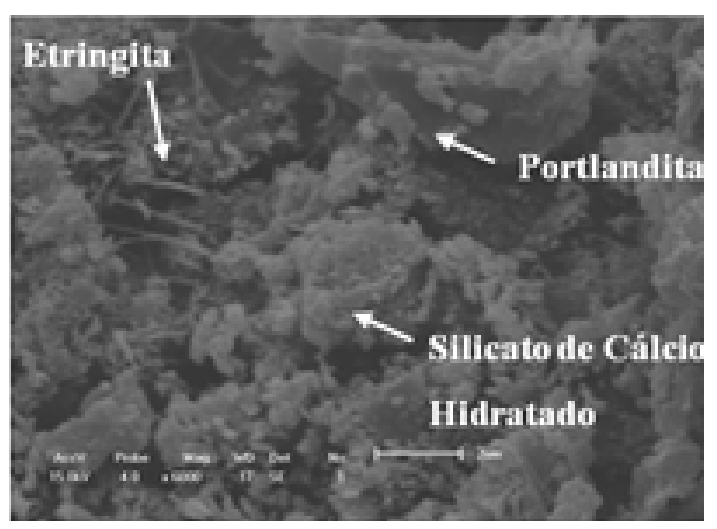

(d)

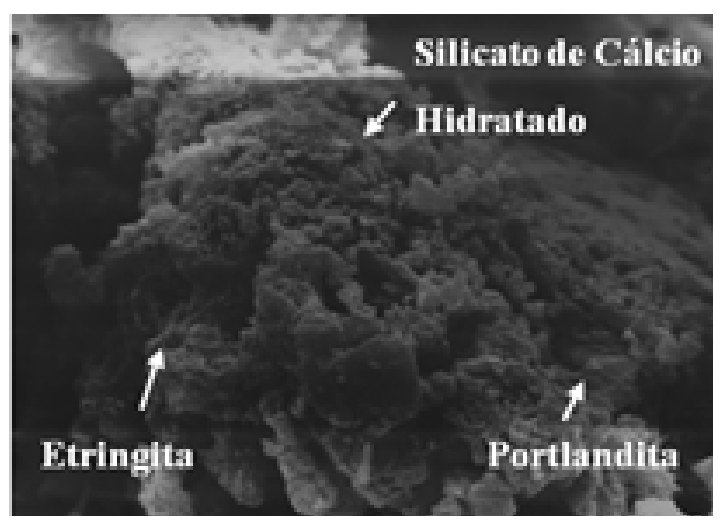

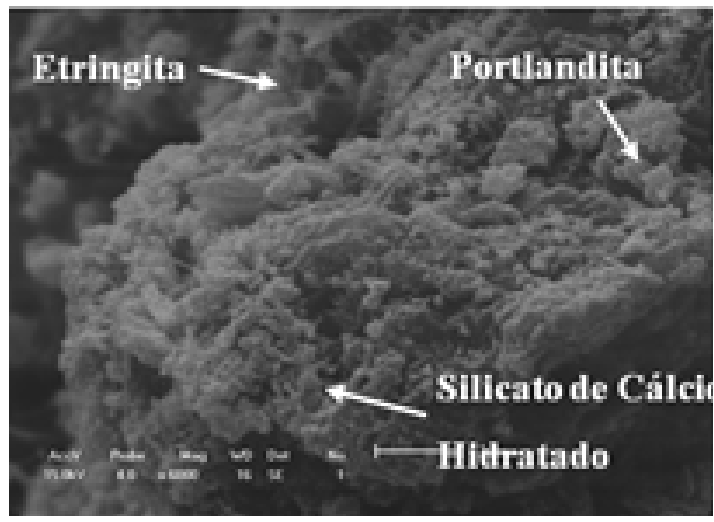

Fonte: Autores. 
Figura 9 - MEV do traço rico

(a)

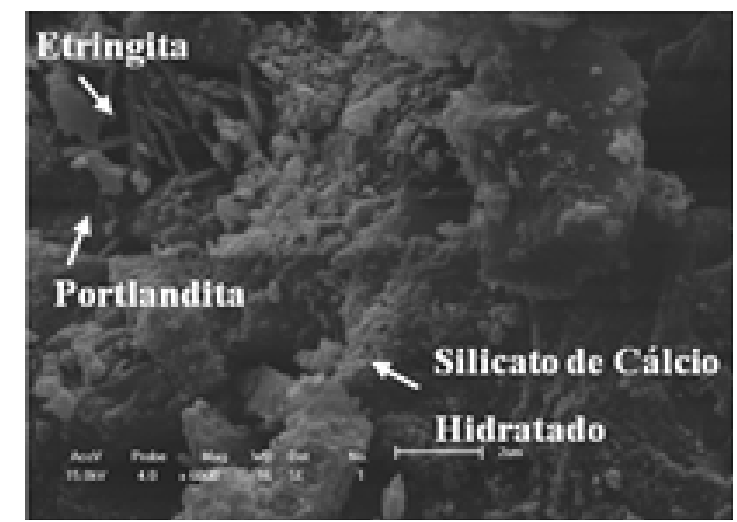

(c)

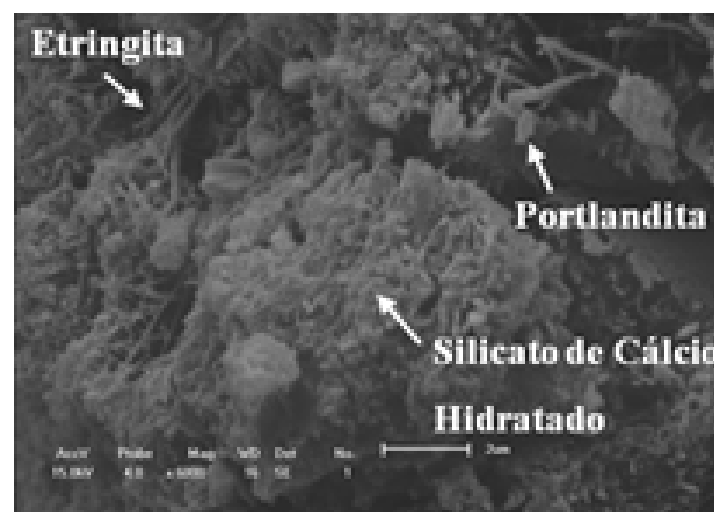

(b)

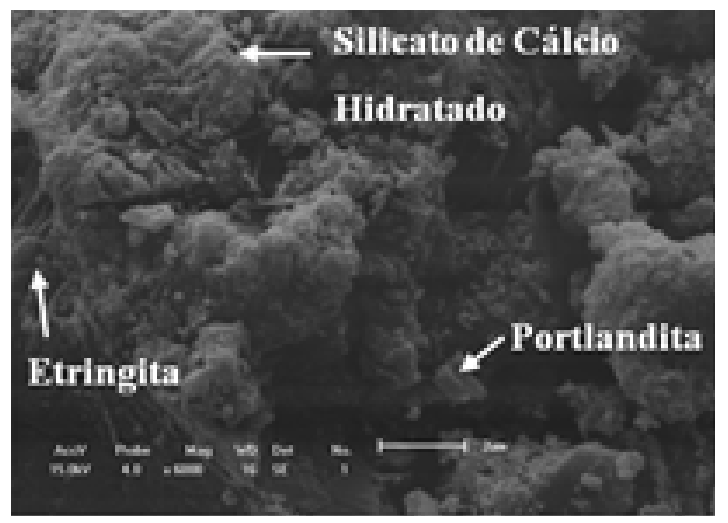

(d)

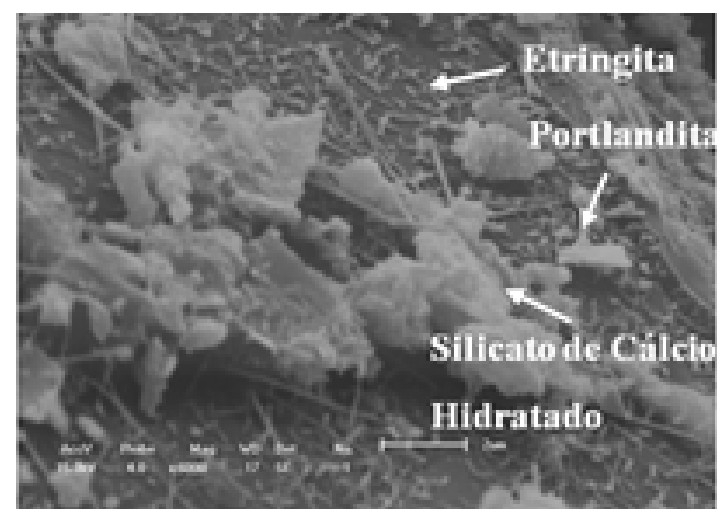

(e)

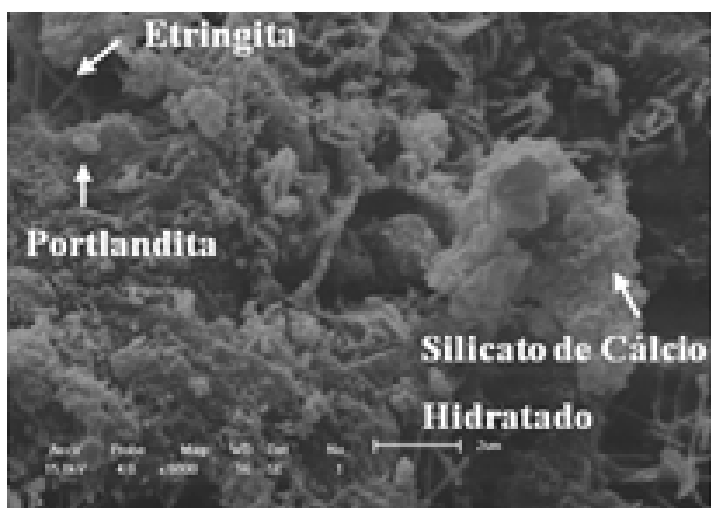

Fonte: Autores. 


\section{CONCLUSÃO}

A viabilidade da utilização do resíduo pode ser analisada por meio de ensaios de resistência à compressão dos corpos-de-prova de concreto para os dois traços com substituições parciais de cimento por cinza. Foi comprovado que a substituição de até $7,5 \%$ no traço normal obteve uma resistência de 29 $\mathrm{MPa}$, valor de resistência semelhante ao concreto sem substituição. Essa substituição também reduziu o consumo de cimento de 367 $\mathrm{kg} / \mathrm{m}^{3}$ para $339 \mathrm{~kg} / \mathrm{m}^{3}$ e o custo em $\mathrm{R} \$ 15,72$, o que é benéfico para o meio ambiente pois a incorporação da cinza no cimento irá reduzir a poluição causada pelas indústrias de cimento durante a sua fabricação e esta consequentemente pode diminuir o consumo dos recursos naturais utilizados no processo. Os ensaios de MEV afirmar que no concreto com traço normal e com substituição de até $7,5 \%$, foi constatada a presença de silicato de cálcio hidratado em maior quantidade que a de etringita e portlandita, o que justifica a semeIhança de resistências obtidas. $E$, também foi observado que quanto mais rico for o traço, maior será a influência da cinza na substituição do cimento Portland para reduzir a resistência mecânica.

Em síntese, conclui-se que a cinza volante do bagaço de cana pode substituir parcialmente o cimento, já este apresentou um elevado índice de pozolanicidade e uma resistência mecânica semelhante para ao concreto sem substituição.

\section{REFERÊNCIAS}

ASSOCIAÇÃO BRASILEIRA DE NORMAS TÉCNICAS. NBR 5738. Concreto - Procedimento para moldagem e cura de corpos-de-prova. Rio de Janeiro, 2003.

NBR 5738. Emenda - Concreto - Procedimento para moldagem e cura de corpos-de-prova. Rio de Janeiro, 2008.
NBR 5739. Concreto - Ensaio de compressão de corpor-de-prova cilíndricos. Rio de Janeiro, 2007.

NBR 7181. Solo - análise granulométrica. Rio de Janeiro, 1988.

NBR 15895. Materiais pozolânicos Determinação do teor de hidróxido de cálcio fixado - Método Chapelle modificado. Rio de Janeiro, 2010.

NBR NM 23. Cimento Portland e outros materiais em pó - Determinação da massa específica. Rio de Janeiro, 2001.

. NBR NM 45. Agregados - Determinação da massa unitária e do volume de vazios. Rio de Janeiro, 2006.

NBR NM 52. Agregado miúdo - Determinação de massa específica e massa específica aparente. Rio de Janeiro, 2009.

NBR NM 53. Agregado graúdo - determinação de massa específica, massa específica aparente e absorção de água. Rio de Janeiro, 2009.

ASSOCIAÇÃO BRASILEIRA DE NORMAS TÉCNICAS. NBR NM 67. Concreto - Determinação da consistência pelo abatimento do tronco de cone. Rio de Janeiro, 2003.

. NBR NM 248. Agregados - Determinação da composição granulométrica. Rio de Janeiro, 2003.

BRASIL. Lei no 12.305, de 2 de agosto de 2010. Institui a Política Nacional de Resíduos Sólidos; altera a Lei no 9.605, de 12 de fevereiro de 1998; e dá outras providências. Disponível em:< http://www.planalto.gov.br/ccivil_03/_ ato2007-2010/2010/lei//12305.htm>. Acesso em: 28 ago. 2012.

FEITOSA, Diego G.; MALTONI, Kátia L.; SILVIA, Ilca P. F. Avaliação da Cinza, Oriunda da Queima do Bagaço da Cana de Açúcar, na Subs- 
tituição da Adubação Química Convencional para Produção de Alimentos e Preservação do Meio Ambiente. Rev. Bras. de agroecologia, Curitiba, v. 4, n. 2, p. 2412-2415, nov. 2009.

MARTINS, C. H.; MACHADO, P. H. T.; ALTOÉ, S. P. S. Produção de corpos de prova de concreto com cinza do bagaço de cana-de-açúcar. In: ENCONTRO TECNOLÓGICO DA ENGENHARIA CIVIL E ARQUITETURA, 8, 2011, Maringá.

NITA, C; JOHN V. M. Materiais pozolânicos: o metacaulim e a sílica ativa. Boletim Técnico da Escola Politécnica da USP. Departamento de Engenharia de Construção Civil; BT/PCC/451, São Paulo, EPUSP, 2007. P 8-9.

NUNES, I. H. S. Estudo das características físicas e químicas da cinza do bagaço de cana-de-açúcar para uso na construção. 2009. 67 f. Dissertação (Mestrado em Engenharia Urbana) - Universidade Estadual de Maringá, Maringá.

SALES, A; LIMA, S.A. Use of Brazilian sugarcane bagasse ash in concrete as sand replacement. Waste Management, Vol. 30, p. 11141122, 2010. 